\title{
O UNIVERSO DA SOCIEDADE DA COMUNICAÇÃO E DA INFORMAÇÃO: UM SENTIDO DA HISTÓRIA E UMA PROBLEMÁTICA ATUAL
}

The universe of information and communication society: a sense of history and a current problematic

Cilene Gomes*

\section{Resumo}

Buscando o entendimento das relações entre ciência, tecnologia e sociedade, o artigo propõe-se a elaborar um sentido da história da sociedade da comunicação e informação, resultando em uma reflexão sobre questões teórico-filosóficas inerentes à contemporaneidade. Os procedimentos adotados resumem-se ao estudo bibliográfico, a constatações e indagação da realidade em que vivemos. Desde tempos remotos, as comunicações e a informação constituem práticas sociais indissociáveis. A motivação de conhecimento e transformação do mundo real é o princípio ativo da evolução das técnicas de comunicação, informática e informação. Os universos da comunicação e informação retratam a aceleração dos avanços científico-tecnológicos dos últimos decênios e a convergência de redes técnicas que estão na base da globalização econômica e da unificação entre cidades, nações e continentes. Mas, se aí temos uma revolução instigante, a problemática da incomunicabilidade e desinformação se apresentam

* Docente, pesquisadora, Estagiária de Pós-Doutorado do Instituto de Pesquisa e Planejamento Urbano e Regional (IPPUR) da Universidade Federal do Rio de Janeiro (UFRJ); mestrado e doutorado em Geografia Humana, pela Universidade de São Paulo. Email: cilenegomes@terra.com.br. 
o universo da sociedade da...

ainda como questões cruciais para o debate acadêmico e a condução do desenvolvimento social.

Palavras-Chave: Comunicação. Informação. Ciência. Tecnologia. Sociedade.

\section{Abstract}

This article intend to elaborate a sense of the history of the communication and information society, resulting in a reflection on inherent theoreticalphilosophical questions of the contemporary times, in order to understand the relationship among science, technology and society. The adopted procedures were bibliographical, verifications, and inquiry of the lived reality. From remote times, the communications and the information are inseparable social practices. The main driven force behind the evolution of information, informatics, and communication techniques is our wish to understand and transform our world. The universes of the communication and information portray the acceleration of the scientific-technological advances of the last decades and the convergence of technical networks that are in the base at the economic globalization and of the unification among cities, nations and continents. But, if we have an inciting revolution, the problem of the incommunicability and disinformation still present some crucial questions for the academic debate and the conduction of the social development.

Keywords: Communication. Information. Science.Technology. Society.

\section{INTRODUÇÃO}

Buscando o entendimento das relações entre ciência, tecnologia e sociedade, o artigo propõe-se a elaborar um sentido da história da sociedade da comunicação e da informação, com o objetivo de delimitar uma problemática que remete a algumas questões de ordem teóricofilosófica a respeito de nosso tempo. 
Parte-se do pressuposto teórico-metodológico da ciência do espaço geográfico e social que subentende, primeiro, o enfoque das relações permanentes entre espaço, técnica e sociedade e, por conseguinte, a peculiar condição do presente momento histórico de um progresso tecnológico inusitado, casado aos avanços do conhecimento científico, com repercussões profundas no processo de reorganização da vida social e de seu espaço. Segundo este alinhamento, o artigo desenvolve-se tendo como objetos os sistemas técnicos e os processos de comunicação e informação que, justamente, constituem os fundamentos deste novo vir a ser da sociedade, hoje vista a título de uma sociedade da informação.

Nesse sentido, a tematização proposta obedece basicamente à estrutura de seus três tópicos principais que, em linhas gerais, propõemse, primeiro, a estabelecer o nexo da relação essencial entre comunicação e informação e uma breve reconstituição da história das técnicas das comunicações humanas, com ênfase nas relações entre sistema técnico e sistema social no século XX.

Em seguida, o estudo pretende destacar, no universo da comunicação, a evolução particular dos sistemas técnicos de informática e informação, engendrando importantes questões para a reflexão, entre outras, a questão da convergência entre sistemas de informática e comunicações na base do processo de unificação social crescente e a questão do processo de valorização social atribuída à comunicação e informação como recurso estratégico para a construção de uma outra sociedade.

Em terceiro lugar, ao final do sentido da história estabelecido, o estudo orientou-se com o objetivo de circunscrever uma problemática atual da vida social, em suas diversas instâncias, que, em última análise, associa-se à questão do uso social de uma enorme quantidade de informações (obtida pelo recurso aos sistemas modernos de informática e comunicação) e, principalmente, ao conteúdo ideológico de um sistema social segregacionista e excludente.

$\mathrm{O}$ artigo conduziu-se graças às assimilações teóricas das leituras realizadas e às observações das inúmeras situações que se nos apresentam cotidianamente. O que nos proporciona uma oportunidade a mais de reflexão em nosso processo de conhecimento da sociedade em que vivemos 
e do próprio homem enquanto chave das possíveis transformações de toda ordem.

\section{UM SENTIDO DA HISTÓRIA DAS COMUNICAÇÕES}

Entre as diversas formas de relações sociais, as comunicações constituem um universo. Da mais imediata comunicação às mais intermediadas, tecnicamente, é todo um espectro de atividades que se desdobra com o processo dos tempos. Irradiadas a partir de um irresistível movimento de avanços científico-tecnológicos, as comunicações favorecem a unificação técnico-cultural de nossos dias, conjugando-se à vida social de ponto a ponto do espaço e nela subsistindo.

Na reconstituição das bases do conhecimento e da ação que promovem a evolução das comunicações humanas e do vir a ser da sociedade da informação, importa direcionarmos a atenção ao domínio da linguagem. A transmissão oral e escrita constitui o primeiro alvo das concepções e meios da comunicação que se desenvolveram, na milenar história humana, sobrepondo-se, naturalmente, aos gestos e expressões corporais e, mesmo, à própria informação da hereditariedade (CHARDIN, 1986, p. 319-320).

Embora a imagem adquira outra relevância na composição das mensagens da vida moderna, a palavra é, ainda, o veículo preferencial da inteligibilidade do mundo real, compondo, em parte, o trabalho exercido em comum (DUCASSÉ, 1945). Corroborando está idéia, Higounet (2003, p. 10) refere-se à palavra escrita enquanto "um meio de acesso direto ao mundo das idéias", permitindo a apreensão do pensamento e fazendo-o atravessar o espaço e o tempo.

Com base nesse pressuposto de que a palavra é, também, em seu sentido primeiro, ação de comunicar ou comunicação, uma suposição proposta é a de que os meios de comunicação evoluem de modo a mobilizarem a informação gerada e organizada socialmente. A crescente motivação de conhecimento do mundo real teria sido o princípio mesmo de toda evolução técnica das comunicações e dos sistemas de informática e informação. A comunicação é uma das condições essenciais da constituição do universo social que, em seu todo e em nossos dias, oferece aos homens as novas possibilidades da informação. 
Confiada a círculos sociais restritos que se ocupavam da transmissão do saber ou dos sistemas de administração e contabilidade, a técnica da linguagem escrita conhece modificações substanciais, quer seja de um tempo a outro, ou de uma a outra cultura, quer seja no que respeita ao seu suporte material, à sua forma ou razão de uso social. Assim, o patrimônio escrito da humanidade tornou-se objeto de um enriquecimento incessante e muito fecundo. Com a invenção e difusão do sistema de alfabetos a técnica da escrita encontra-se hoje praticamente ao alcance de todos os homens, amoldável que é aos mais diferentes modos de pensar e agir.

Das suas primeiras aplicações práticas a uma familiaridade com a escrita em larga escala, um longo processo de transformação dos modos de produzir, difundir e ensinar teve a sua vez na história das técnicas da comunicação. Apoiadas nessa base elementar, entre outras, como a oralidade e a leitura, as próprias técnicas de instrução puderam ser aperfeiçoadas e amplamente propagadas.

Nesse contexto evolutivo, os contatos ou as comunicações que se estabelecem com os mais estimulantes centros ou personalidades da formação e difusão cultural respondem pela ascendente vitalidade do espírito humano. Templos e palácios, bibliotecas, mosteiros, universidades, civilizações urbanas de todos os tempos constituem esses territórios ou essas fontes vivas da comunicação onde todo um universo da informação tende a ser constantemente explorado e redescoberto.

Às portas de um mundo em franco processo de intercâmbios e de um humanismo sempre posto a renascer com as novas aspirações, interesses e exigências culturais que podem resultar (ou que resultam, de fato) de uma ausência de barreiras à mais livre ou plena comunicação, tanto os avanços técnicos introduziram novos pontos de apoio para o desenvolvimento de capacidades até então ignoradas como nos conduziram a novos estágios de consciência do mundo real.

Nessa escalada, a evolução da imprensa e a produção de livros em larga escala constituem apenas alguns referenciais de uma necessidade social cada vez mais evidente de informação, no dizer de Giovannini (1987, p.144), consolidando a transição histórica para uma "cultura da mídia", ou simplesmente, a travessia da sociedade ao seu futuro. Nessa trajetória aos 
nossos dias, à base de muitas notícias e maior acessibilidade das teorias científicas, "era fértil o terreno onde as inovações técnicas do século XX começaram a operar" (Idem, p. 150).

A telegrafia, a telefonia e a radiocomunicação não só contribuíram em muito para fazer da imprensa um dos mais significativos meios de comunicação de massa, como constituíram domínios da técnica ao mesmo tempo distintos e complementares, nesse revolucionário período da história, em que as utopias idealistas e científicas, sobretudo as que aspiravam vencer as grandes distâncias, se tornaram, pouco a pouco, invenções, projetos técnicos, empreendimentos, espaço e sociedade remodelados.

Ainda que o processo de invenção fosse então freqüientemente desacreditado, graças aos princípios da eletricidade e do magnetismo recém-desvendados, e a inúmeros outros conceitos básicos e experimentos, muitos resultados foram alcançados no sentido de uma melhor comunicação entre cidades, nações e continentes. Em paralelo a esses sucessos progressivos, o campo da mobilização da informação noticiaria amplia-se consideravelmente.

Dos sistemas de linhas unindo "ponto a ponto" do espaço a técnica das primeiras telecomunicações logo evoluía para o sistema de redes, comandado por uma unidade central de endereçamento de mensagens. Nesse progresso, a possibilidade de transmissão das ondas eletromagnéticas e a automatização dos sistemas de comutação foram duas importantes conquistas técnicas que vieram influir, junto a outras descobertas, nas mudanças radicais do sistema de comunicações em nosso século.

A invenção do rádio, a emergência da publicidade, a empresa jornalística, as novas mídias, o advento do computador, a engenharia eletrônica, os satélites, a força da imagem, a potência das novas transmissões são alguns, entre outros, dos novos ingredientes de uma verdadeira revolução que se apresenta ao homem como um dos desafios mais instigantes da história no que possibilita e deve engendrar para o futuro.

\section{Sistema técnico e sistema social no século XX}

A atual sociedade da comunicação tem se constituído no último século através de um forte empenho social dado à investigação nos domínios 
científico e tecnológico. Ciência e tecnologia ${ }^{1}$ começam a interdepender sob o impulso vigoroso de uma sociedade cada vez mais interessada em um melhor conhecimento do mundo e, portanto, cada vez mais envolvida com o trato da informação. Através dos novos progressos na pesquisa dos sistemas teóricos básicos e das aparelhagens para a comunicação, alteraram-se não somente os padrões relacionais e de organização do trabalho, mas também, e por isso mesmo, da vida social no seu todo.

É em meio a uma sociedade bem mais ciente dos fatos e acontecimentos do mundo e de uma circulação de idéias e conhecimentos em circuitos mais amplos da atividade científica e da criação técnica que as estreitas relações entre os novos sistemas de comunicação e a remodelação do espaço público e privado dá-se a conhecer melhor. E é nessa ordem de idéias ou de relações entre técnica, espaço e sociedade, que também se situa a proposta desenvolvida por Flichy (1993).

Ora, é nesse contexto de relações conceituais que o estudo citado nos leva a observar a importância e a necessidade de uma estrutura social apropriada para que certos desenvolvimentos técnicos possam avançar. O crédito ideológico depositado na comunicação a distância e o apoio institucional e financeiro para a construção de um sistema técnico, revelando a figura de agentes sociais interessados, teriam sido, assim, forças propulsoras sempre presentes em toda a evolução das telecomunicações e dos sistemas de informação do século. Como demonstra Flichy (Idem, p. 22-23), a adoção de uma técnica é, então, presidida por uma idéia florescente em um preciso círculo de interesses sociais ou de usos previstos.

Assim, no marco dos propósitos militares e políticos (do Estado moderno) de encurtamento das distâncias (e com isso as comunicações rápidas), para a consolidação da unidade do espaço nacional e instrumentalização do serviço de guerra, os aperfeiçoamentos da telegrafia foram sustentados.

Começava, então, uma das mais notáveis revoluções de nosso tempo, com suas novas medidas de duração e empresas da racionalização (Ibid, p. 26).

Nesse transcorrer da história, os avanços do pensamento humano e da evolução científico-técnica foram alcançados graças a uma investigação 
de grande magnitude concentrada no objeto universal ou "mecanismo da natureza”, a matriz de toda ciência (FLICHY, 1993, p. 31) e do desenvolvimento tecnológico hoje disponível.

Com a progressiva imposição de uma economia regulada pelo mercado, a um deslocamento das sucessivas gerações técnicas vieram corresponder, historicamente, novas demandas de uso social dos sistemas criados, tais como, a dos bancos e da bolsa de valores, a demanda relativa à gestão dos transportes (inclusive o de mensagens), a dos jornais, das indústrias etc. A esse propósito, Flichy nos mostra como o liberalismo teria constituído um quadro favorável não só para o desenvolvimento comercial, mas também para o processo de inovações no contexto da organização dos sistemas de transportes, telecomunicações, distribuição etc.

Da investigação científica à exploração comercial; das ações de múltiplos interesses às novas técnicas concebidas e criadas; dos enlaces urbanos às mais recentes configurações de redes interconectadas na escala mundial, é todo um transladar de evoluções simultâneas que convergem ao ponto crítico em que um outro conjunto de aspirações e conceitos parece poder desencadear uma nova conscientização da real dimensão e do valor das comunicações e da sociedade da informação.

Paralelamente a essa tendência a uma universalidade dos sistemas técnicos, ou, à "unicidade técnica” (SANTOS, 1996, 2005), também evolui a regulação dos sistemas de comunicações à distância, tanto no plano nacional quanto no internacional. Sob a condição de normas adequadas à funcionalização dos sistemas técnicos, acordos e organismos internacionais de natureza técnico-administrativa passam a ser firmados, assim como estatísticas de utilização dos sistemas técnicos começam a ser elaboradas.

Na referência ainda ao estudo de Flichy (1993, p.61), na sucessão de deslocamentos que levam a pesquisa científica do universo de um indivíduo isolado aos grandes centros de investigação de nossos dias, é todo um aparato de suposições e instrumentos que ultrapassa as fronteiras de um pequeno laboratório ou gabinete e, associando-se a um deslocamento de uso social, estreita-se aos novos contornos do empreendimento das comunicações. 
Junto a esse fenômeno, reaparece com nitidez a ampla necessidade de circulação informacional, tal como Santos (1996, p. 202) se refere a uma "explosão do espaço de cada qual" quando fala de "um alargamento de contextos" associado "às novas possibilidades de fluidez" de nossa época.

Flichy também nos chama a atenção para a relevância da informação na constituição dos mercados - 0 que certamente teria contribuído para a expansão do mundo colonial. Transcrevendo o que diz Stanley Jevons, Flichy (1993, p. 72) reafirma a idéia de que "um mercado pode existir sem lugar fixo de intercâmbio, se há uma comunicação estreita entre os participantes de uma transação".

Sob o contágio das novas idéias científicas e das numerosas inovações técnicas que marcaram, no campo da comunicação e da informação, a passagem ao século XX, todo um outro âmbito da vida social tende a ser alcançado, para além dos grandes agentes usuários. Já quando os novos meios de comunicação começavam a interferir no surgimento de uma opinião pública e nos interesses das ciências e das artes, uma transformação tende a se processar tanto no âmbito da vida profissional como familiar.

Desde então começa a se delinear o que, em larga amplitude e em pouco tempo, se chamará de sociedade do consumo de massas. Assim é que não só o telefone e o rádio, mas também os diversos meios de captura de sons e imagens (como a fonografia, a fotografia, o cinema e, mais tarde, a televisão e mesmo o computador) tornaram-se os novos objetos de uso social e de um novo espaço que se remodela na esfera da vida pública e privada. Como nos faz entender Santos (1996, p. 143), "as novas tecnologias envolvem muito mais gente e colonizam muito mais áreas (...), estão presentes nos lugares mais ermos e invadem nossas casas".

\section{A QUESTÃO DA INFORMAÇÃO}

No último século, a evolução que conhecemos das engenharias da comunicação e da informática deve-se muito aos avanços de uma ciência geral da informação, tornados possíveis graças à importância social 
crescente atribuída, como temos visto, aos processos de memorização e difusão da informação. De fato, o contexto sócio-cultural impulsiona decisivamente o processo de inovação e de estabelecimento das condições de uso dos sistemas e objetos técnicos criados.

Seguindo essa ordem de idéias, um processo e sentido da história tendem a ser refeitos à base de uma precisa organização de recursos e de ocupações e, afinal, no alcance de uma unificação técnico-social sem precedentes. A tal ponto chegam a se impor os progressos das ciências do mundo natural e técnico que não somente o universo, ele próprio, torna-se efetivamente ilimitado enquanto razão de investigação e possibilidade de prolongamento técnico. A técnica em si tende a constituir um novo ponto de debate para a sociedade. E é então no objetivo do reconhecimento de suas novas eleições e seus esforços concentrados que a sociedade vai se remodelando e se refazendo como espaço de comunicação e informação.

Sim, eis que, agora, a informação é ao mesmo tempo a fonte e a energia, a matéria e a construção, a técnica e a sociedade. A informação é a medida de escolhas e de valorização que importa a um tempo (GOMES, $2001,2002)$. A informação justifica as novas aspirações que nascem em meio a uma humanidade cada vez mais ciente de seu universo. A informação tornara-se a grande técnica articuladora das técnicas de nosso tempo (SANTOS, 1996).

A partir desse ponto de definição, ensaiemos um novo percurso da história em vista de retratar a informação a modo de tempos e espaços, de um corpo de técnicas e de uma notável tendência à codificação dos processos de comunicação.

Talvez pudéssemos considerar que, em seus primórdios, a informação não passa de uma possibilidade de descoberta do mundo real, um terreno que se prepara para o grande acontecimento da comunicação social de nossos dias. Em toda sua dimensão e movimento, o universo da criatividade, da expressão e, mais especificamente, da comunicação têm, então, na informação o seu elemento agregador.

Em Breton (1991, p. 37) algumas referências podem ser encontradas para uma reflexão sobre o papel da informação na vida social. O autor levanos a pensar, por exemplo, no nascimento da noção de informação entendida 
como "um conhecimento que podemos elaborar, argumentar e, sobretudo, um conhecimento transmissível, notadamente pelo ensino". Retomando o sentido original do termo moderno na palavra latina "informatio", faz associar à "ação de dar uma forma” ao domínio técnico ou de construção material e ao universo do conhecimento a designação de ensinamento, instrução, idéia, noção, representação.

Breton (1991) nos mostra também como a noção de informação veio se precisar em dado momento de ascensão da cultura latina, em que a comunicação tende a ser valorizada, pela prática da oratória e retórica, como objeto de aprendizagem e garantia para o caminho de responsabilidades do cidadão. Nesse sentido, o autor considera ser a informação fundada na idéia de organizar a comunicação como palavra para o outro. Também, situando a atmosfera do pragmatismo ou desconfiança geral das abstrações e de generalizações, termina nos indicando o trajeto histórico da informação no percurso da palavra ("logos") que se transforma em cálculo ("ratio") (Idem, p. 38 a 41).

Nesse entretempo são notáveis as mudanças intelectuais e sociais que irrompem no limiar de um outro mundo. Em detrimento do papel de leitor e comentarista dos textos sagrados, o intelectual ascende como humanista e "artesão que descobre, trabalha com as idéias, submete-as a uma crítica ao fazê-la circular" (Ibid, p. 52).

Tendo o livro como suporte de uma nova técnica (a da impressão) ou veículo de transmissão, a idéia transfigura-se em informação, em um objeto de comunicação, "um objeto mental que pode ser transportado, transferido, enriquecido, verificado". Como nos diz ainda o mesmo autor, nesse prenúncio das formas modernas da comunicação social, o livro introduz a idéia em um circuito mercadológico, já que, igualmente, transcorre o tempo em que o espírito mercantil e do desenvolvimento técnico exercem um imenso atrativo para a preocupação com a cultura material (Ibid, p. 52).

Dessa circulação informal de idéias - que se efetiva, a modo de informações, e conduz ao progresso de uma razão crítica - ao projeto contemporâneo de uma sociedade da comunicação -, outras tantas são as linhas de convergência entre a técnica e a sociedade e, assim, entre a ideologia e a modelação do espaço do homem. 
A rigor, são em bom número e de nova significação as confluências que se pode depreender desse novo arranque da história. Todos os movimentos sociais se encaminham ao tempo em que a informação e a comunicação passam a constituir valores fundamentais. As causas revolucionárias e doutrinárias encontram o seu apoio nas técnicas de difusão social. Como nos faz ver Lévy (2001, p.23), "as grandes agitações políticas do século XX podem ser interpretadas como peripécias da crise de unificação". A necessidade de propagação e o confronto de expressões e opiniões despontam em meio a uma sociedade que tende a participar mais do debate social e a primar por uma nova forma de comunicação religando os espaços dos indivíduos tornados cidadãos. O domínio da comunicação torna-se tanto o reflexo das atitudes de liberdade como um sinônimo do exercício e legitimação do poder político. É Lévy (2001, p. 27, 157), mais uma vez, quem desenvolve esta idéia de que a interconexão é condição para o poder e a expansão da consciência.

Paralelamente, o avanço das ciências exatas e experimentais, realizado na base de evidências, tende a exercer outra influência nas modalidades comunicacionais de inspiração racionalista e mecanicista. A era do automatismo industrial tem início e, logo, não só progridem a mecanografia e as primeiras máquinas informáticas, mas igualmente os sistemas de codificação e os meios de transporte da mensagem.

De fato, é em função da informação pronta a circular que a comunicação social se organiza e que as gerações técnicas se sucedem. De linha a linha de transmissão e a todos os azimutes, a comunicação social se transforma graças à evolução do telégrafo e do telefone, a uma imprensa que se apropria desses meios técnicos, aos novos meios via rádio, ao rumo que tomarão as técnicas eletrônicas e os sistemas computacionais. Dessa forma, uma intensa atividade de circulação de idéias e informações, também relacionadas aos crescentes movimentos de mercadorias e deslocamentos de pessoas, tende a demarcar uma nova lógica e linguagem dos tempos, novos problemas técnicos e novas perspectivas teóricas e sociais.

No dizer de Breton (1991, p. 85), "com o computador, o modo de existência de uma informação se equipara inteiro ao seu movimento", mesmo a armazenagem que constituiria, então, um caso particular desse 
movimento. A natureza técnica do computador não se distancia do fato de ser uma máquina dotada de um sistema de unidades ou componentes (memória, cálculo e controle) que, à base de programação, organiza automaticamente todos os movimentos internos da informação. Associado ao mundo do telefone, essa intercomunicação interna, ou gestão dos deslocamentos de informação que o computador veio possibilitar, se prolonga e se alarga e consolida o novo princípio da transmissão em rede (Idem, p. 82 a 85).

É praticamente em tempo simultâneo que prosperam as bases conceituais de uma máquina para 0 tratamento da informação (John von Newmann) e uma máquina para a comunicação (Norbert Wiener) ${ }^{2}$. A informação passa a se definir como função de comunicação. E o computador torna-se a unidade central de um novo complexo de técnicas cada vez mais susceptíveis ao funcionamento integrado. Os novos sistemas técnicos caminham, assim, para uma mais alta compatibilidade, sem o que a comunicação torna-se bastante dificultada ou mesmo impossível.

Esse será o pressuposto fundamental para que um elo viesse se estabelecer, a partir de meados do último século, entre os três grandes territórios da comunicação moderna: as mídias, as telecomunicações e a informática, tal como nos faz ver ainda Breton (1991, p. 89). Fundada na ideologia da comunicação e na tendência da técnica de digitalização, essa convergência entre diferentes modalidades comunicacionais será o novo ponto de partida para um processo mais amplo de novas reflexões sobre o fenômeno total da comunicação humana, da linguagem, da cultura, das representações que a sociedade faz de si mesma etc.

Remonta aos anos 50 a idéia e o discurso de que a informação e a comunicação constituem os mais novos valores da modernidade, sem os quais a organização social seria levada ao risco do insustentável. Breton atribui à emergência dessa ideologia a situação crítica a que chegara a humanidade com o avanço dos totalitarismos e das grandes guerras mundiais. A alternativa de alimentar a idéia de uma sociedade da comunicação teria se imposto para desarmar o estado reinante de ameaça de autodestruição que vigorava na época.

Apoiada nos fundamentos teóricos da história da informática, então em franca ascendência, e, sobretudo, na grande influência que teria tido 
a cibernética nos meios intelectuais dos anos 70, a comunicação tornase uma das mais essenciais finalidades da nossa sociedade: estratégica para o desenvolvimento econômico e o exercício político, e privilegiada para assegurar a coesão sóciocultural dos indivíduos em coletividade. Toda espécie de problema estaria em vias de resolução no recurso à comunicação social.

Para a cibernética a grande ameaça real advinha da força desagregadora que supõe a entropia. Em um mundo complexo e potencialmente exterminável, o controle, dado pelo domínio da informação, e as comunicações tornaramse os mais importantes objetos de estudo e apropriações pela técnica. Segundo essa base lógica, o uso do computador passara a representar uma necessidade e, mais do que isso, o símbolo de uma incomparável revolução técnica, social, mental, cultural. Um novo sistema de valores e representações do mundo conjuga-se ao desenvolvimento das técnicas e das formas de uso social.

Em meio aos mais variados círculos de atividade e às mais distintas práticas de expressão comunicacional, dia após dia o computador se alastra e se incorpora na vida social criando expectativas e novas desigualdades, suscitando debates e remodelações.

Dado o vasto campo das relações sociais, é na particularidade de um mundo mediatizado pelas novas técnicas da comunicação e da informação que a atual força da globalização tende a se evidenciar (MONTIEL, 2003, p. 159). Novas práticas sociais e profissionais tornam-se cada vez mais tributárias desses meios técnicos e, com, isso, a comunicação social ascende como norma para os modos de pensar e agir. As mídias influem decisivamente como mecanismo indispensável para a funcionalização da sociedade de mercado, onde se assenta a fabricação do homem moderno.

Se essa representação alterada da pessoa humana e de sua participação na sociedade conduz ao desenvolvimento da comunicação, o faz, na expressão de Breton (1991, p. 116), a preço de uma "colonização ideológica", que "perpetua" a oferta de estilos de vida praticamente afeitos a estereótipos e ao conformismo. No contexto de mercados ampliados e esquadrinhados pelos sistemas de informação, a publicidade torna-se o grande suporte econômico das mídias e da difusão sugestionadora entre produtores e consumidores. 
Os meios de comunicação de massa tornam-se um dos grandes filóes do consumo moderno. Em função desse atrativo, o tempo social se impõe e articula de modo diferenciado, ocasionando mudanças na experiência psíquica e na esfera dos comportamentos. O tempo destinado a outras atividades é muitas vezes suprimido pela hegemonia dos horários e programações e pelos instantes que uma imagem bem produzida leva a cativar. Quer se busque a informação ou o entretenimento, a estimulação intelectual ou o convívio costumeiro de uma grande família nacional, os veículos de massa seguem propagando a sua herança e seu modo de fazer cultura. Envolvendo novos agentes e profissões, trabalhando a sua específica informação e alcançando os seus próprios territórios, as novas mídias têm marcado forte presença no jogo intrincado e astucioso da comunicação moderna (MONTIEL, 2003).

Nesse domínio global de uma atividade comum, os meios de comunicação a distância configuram um outro território. Cumprindo a função de transporte de mensagens, as telecomunicações assumem grande importância no processo de integração das técnicas de comunicação e na dinâmica de expansão dos serviços (GOMES, 2002). Propiciando a movimentação dos fluxos de informação, os sistemas de telecomunicações resultam de uma das engenharias que mais contribuíram para a investigação de uma equiparação possível entre o homem e a máquina e, mesmo, na pesquisa das relações entre o homem e a natureza das mensagens que faz circular.

Mas é na associação com os sistemas de informática que as telecomunicações constituem um novo potencial para a reorganização social e do espaço. $O$ processamento da informação de qualquer natureza tornase indissociável das suas terminações comunicacionais. Em todo alcance geográfico, os sistemas espaciais construídos pelos homens são a evidência completa dessa conjunção de redes técnicas distintas que os sistemas de telecomunicações e informática configuram e coordenam. Mas não apenas isso, pela natureza dos novos fluxos e interações informacionais, revelam 0 próprio modo de ser da sociedade de nossos dias.

No contexto de um novo domínio científico entreaberto, os argumentos em favor da nova sociedade da comunicação suscitavam a esperança de 
uma outra comunidade nascida da guerra fria. A colaboração de cientistas e militares no plano do desenvolvimento da informática não impediria a nova ebulição intelectual que a cibernética veio contextualizar impulsionando o florescimento de uma nova concepção de técnica e sociedade.

É revisitando o próprio homem como modelo e mensagem, como informação e via de comunicação que a nova utopia formulada por Wiener e adeptos da cibernética chegam a propor nada mais do que uma redescoberta do homem mesmo no cerne de toda atividade inteligente, organizada e de suas relações com o meio social e esfera da criação. A imperfeição, o acaso, a desordem, eis a força inimiga da humanidade. Para a cibernética, a comunicação seria "a solução porque só a ordem, a organização, concebida como troca de informações permite superar a entropia” (BRETON, 1991, p. 214) e pilotar o mundo social.

Paralelamente ao estudo do princípio do feedback do comportamento de trocas de informação, aprimoram-se as investigações de uma máquina dotada de maior autonomia (Turing) e comunicabilidade. À luz de um novo espírito de abertura à comunicação e à transparência das relações sociais, que vinha contestar a política do "segredo" e a hierarquia centralizadora da primeira geração da informática, nasce a nova esfera de objetos técnicos, tendo à frente o microcomputador - símbolo maior do potencial de acesso à cultura informática alcançando a toda gente.

Assim, não somente o objeto técnico ou a técnica mesma assume o seu lugar central na vida cotidiana, mas também uma nova linguagem e um novo modo de pensar. A informação e a comunicação parecem se consolidar como valores, que se interpõem no debate crucial acerca do problema da formação das novas gerações (de jovens e profissionais) e da sensibilização do grande conjunto social para as reais possibilidades de construção do futuro que o acesso à informação poderá significar.

De fato, os anos 80 e 90 ascendem com o recurso dessa nova forma de energia social que subentende a informação. Constitui, hoje, o verdadeiro instrumento de união entre as diversas partes da sociedade e do território (SANTOS, 2005, p. 140). O sucessivo processo de informatização impõe a sua lógica de uso social e em função disso, a organização da produção de novos bens e serviços se reformula como tempo e como norma, e incide 
em novas práticas de agregação, de pessoas em atividade, informações, conhecimentos e, também, dos elementos materiais de funcionalização do espaço. Os sistemas de redes se distribuem pelo território e estabelecem a base para uma organização social cada vez mais centrada na circulação da informação.

Mas que modos de comunicação tendem a estabelecer? A que conduz as formas modernas de comunicação? A que espécie de comunidade?

Não parece simples encontrar as respostas para essas questões. Ainda que possamos mesclar a escolha de alguns critérios com alguma sensibilidade, algo sempre poderá nos escapar quando se trata de avaliar os modos comunicacionais de nossa sociedade, tão essenciais que são para reconhecermos a natureza mesma do modo de vida dessa mesma sociedade. Tornar-se ciente desse fenômeno tão valorizado socialmente quanto vital para o crescimento humano e cultural não é, de fato, algo que se alcance com base em um conjunto de informações ainda que abundante, estático. A sociedade vive hoje em meio a um montante de informações, que assombra por sua força de imposição, ou, como sugere Santos (2000), por sua "tirania".

Não é todo esse suporte físico de informações que nos conduzirá a uma informação na sua qualidade de representação do real, de sentido do mundo em que vivemos. É somente na construção de um enfoque unitário do fenômeno da comunicação humana que a informação se revelará em sua mais plena realidade de ser um processo, de se dar como um processo e então, mais uma vez, como medida, como escolha do mais acertado a uma situação e a um tempo.

Como elaborar esse enfoque unitário dos fenômenos da informação e da comunicação se não levarmos em consideração o seu lado interno e externo, a sua inteira realidade? A natureza da mais verdadeira comunidade humana depende de seu "modo intrínseco de comunicação" (BRETON, 1991, p. 216), que poderá prosseguir em um ou outro caminho, em busca de um ou outro alvo. Essa é a liberdade dada ao homem: escolher o seu caminho, o seu modo de comunicar, a comunidade que aspira ver se edificar e ajudar a construir. Qual a precisa informação que mobilizaremos para promover o modo de comunicação social, a comunidade desejável? 


\section{O PROBLEMA DA DESINFORMAÇÃO}

Partindo da palavra em si, podemos conceber a desinformação simplesmente como a condição de uma sociedade ou parte de seus integrantes que vivem sem a informação que thes seja adequada - a informação obtida a seu tempo para o enfrentamento das diferentes situações que lhes sucedem como experiência. Mas a rigor, são diversas as significações que cabem a esse fenômeno intimamente relacionado ao problema da incomunicabilidade humana.

Tudo o que cria uma separação entre as sociedades ou os homens e a informação ocasiona a desinformação. Se a informação é hoje o elemento determinante na remodelação do espaço geográfico ${ }^{3}$ e, mesmo, um instrumento de união, a desinformação é a manifestação típica do espaço dividido ou fragmentado. Talvez possamos conjecturar que, se os lugares tornam-se cada vez mais individualizados em meio a uma organização em massa (FLICHY, 1993, p.95/96), longe nos encontramos ainda de uma autêntica socialização.

Nesse sentido, a desinformação reina onde uma ruptura tende a se estabelecer ou se estabelece de fato na busca de informação concebida como processo, como sentido da história, como capacidade de aprendizagem constante, como virtude dinâmica do entendimento. Não se trata de apenas medir 0 acesso às informações para afastarmos as suposições da desinformação. $O$ fenômeno poderá estar sendo verificado até mesmo em meio a uma cultura ou camada social bem posicionada e de recursos materiais confortantes, e talvez nem tanto em contextos em que aparentemente sobrevive uma população completamente despojada de modernidades ou resistente a elas (GOMES, 2001; PLONSKI, 2001).

Talvez possamos conceber a desinformação também como um processo característico de sistemas sociais fechados ou deterministas, que conhecem a neurose de estocar a informação pelo simples hábito de viver em meio a um amontoado de coisas ou pela atitude que não leva a nada de segurar as informações impedindo a sua mobilização e o seu compartilhar. Trata-se mesmo da questão de "uma distribuição desequilibrada dos conhecimentos” (PLONSKI, 2001). 
A desinformação floresce: onde vigora a descontinuidade temporal de uma sociedade que vive no plano da conquista da vantagem imediata, do supérfluo, do efêmero; onde a mídia e o consumo exercem a sua temível influência, a sua terrível pedagogia; onde as relações sociais tornam-se cada vez mais fundadas na intimidade de uma "psicoesfera" (SANTOS, 1996) atuante por seus prejulgamentos e expressões refreadas sob o domínio manipulador e vicioso da persuasão, da negatividade e, até mesmo, da mais irrisória cultura.

Quanto essa história de notáveis desenvolvimentos científicos e tecnológicos não tem criado de subprodutos ou desperdícios, de situações nos quais a inexistência de comunicação e a desinformação são evidências ou realidades mais ou menos encobertas? O que pensar de uma sociedade cujos integrantes se comunicam e trocam informações intensamente e, todavia, permanecendo tão afeiçoados a enganos, tão alheios ao sentido global da própria história?

A serviço de uma máquina ideológica, a informação aprisiona e se torna totalitária. A desinformação subsiste, assim, a modo de deformações ou deturpações do noticiamento ou conhecimento da realidade. Talvez seja mesmo válido pensar, como sugere Breton (1991), que a "douta ignorância" da idade medieval tenha, muitas vezes, voltado de fato a reger os modos de instruir, informar ou comunicar, pois não é raro nos defrontarmos com sistemas de ensino ou de propagação de mensagens que cultuam tão somente $o$ aprendizado do que interessa ao que prescreve uma dada "regra" - tal o saber de uma dada irmandade religiosa ou de um qualquer clericalismo político, cultural ou filosófico, tal a racionalidade de um coração nada ensinável.

Dessa forma, a desinformação reside junto ao mais cruel de nossos inimigos, a profunda ignorância do que são os lugares, do que é o mundo de hoje, em toda a sua realidade e possibilidade de futuro. Seria o desconhecimento pela ignorância, no dizer de Plonski (2001). Convidando a percepções fragmentadas e a um discurso único do mundo (SANTOS, 2000 , p. 44-45), a desinformação destitui o ser humano da intensa emoção de persentir e explorar o reservatório de descobertas que subentende 0 universo real em toda a sua permanente incognoscibilidade. 
De certo modo, talvez ainda possamos considerar que da impossibilidade de comunicação e da desinformação derivam muitas das mais lastimáveis situações de desagregação social. Nesse sentido, Plonski (2001) situa uma outra forma de desconhecimento com origem na prática política e social prevalecente que tende a construir muros e sistemas de controle dos mesmos em quantidade crescente. Daí a razão de Siqueira (2004) ao apontar a "necessidade de se romper com a fragmentação" da sociedade. Sim, porque tais anteparos à plenitude da vida social e humana impedem a mais autêntica renovação da consciência, que é o único alimento que não conduzirá a humanidade a naufragar na reflexão e esperança de seu amanhã (GOMES, 2001).

A desinformação pode se manifestar não só no plano da visão filosófica ou da mentalidade cultural das sociedades e das pessoas, mas de igual modo nas concepções científicas e nas práticas sociais de diversa natureza. As forças do convencimento alastram-se por todos os domínios da comunicação social, travestidas de intolerância e dos mais diferentes fundamentalismos, de interesses e ambições e de uma retórica da modernidade sem igual. Elas podem estar tanto a serviço da desinformação política ou das diversas práticas associativas, assim como da formulação das ciências sociais e humanas que, dessa forma, também terminam por elaborar ou transmitir uma informação falseada da realidade induzindo a erros de apreciação e a decisões equivocadas.

$\mathrm{O}$ que afinal importa ressaltar, nessa tentativa de problematização, é que o entendimento do mundo e do país em que vivemos tende a ser distorcido (SANTOS, 2002) pelo efeito de uma total falta de informações ou de uma informação errônea ou tendenciosa e, portanto, não condizente à amplitude e diversidade do mundo real. Em que medida fazemos um retrato desfigurado da realidade de nosso tempo e do lugar em que nos encontramos? Em que medida enxergamos o mundo real pela óptica préfabricada das mídias modernas, pelos agentes de um modelo econômico tão sedutor quanto implacável e por uma conscientização política ainda tão distante do que respeita à mais conseqüente cidadania.

Felizmente, o mundo real não é feito apenas de tanta adversidade. São muitas também as manifestações da impossibilidade de participação em 
um mundo tão envolto em falácias e contendas, em filosofias que enredam e não libertam, em causas que teimam e não combatem pela mais vigorosa transformação. São muitos os renovos de uma outra mudança qualitativa em vias de emergir. Quer seja por suas carências ou experiência da escassez (SANTOS, 2000, p. 130-131) em que vivem, a fragilidade de muitos poderá de fato se tornar a grande força da nova história que se prepara e começa nesse nosso tempo de transições.

\section{CONSIDERAÇÕES FINAIS}

Nesta ordem de idéias, e a título de algumas considerações finais, de fato não podemos deixar de explicitar as relações de uma sociedade da informação organizada em rede, que evolui a caminho de uma sociedade do conhecimento. A este propósito, um ponto importante a ser ressaltado é o que bem retrata Szabo e Silva (2007, p. 38, 42). Quando analisam o uso da Internet, contrapõem, na sua relação dialética, a supervia da informação, de uso coorporativo e estritamente mercantilizador, às práticas de comunicação de caráter cooperativo e comunitário, dando maior amplitude ao uso social da rede de computadores e favorecendo o fortalecimento dos movimentos sociais, no sentido de uma sociedade do conhecimento a serviço de uma cada vez maior conscientização acerca das inesgotáveis possibilidades de agir e transformar.

Ora, nessaabordagem, coloca-se em primeiroplanoa rede deinterações de natureza diversa constituindo um espaço de fluxos comunicacionais e/ ou informacionais que, na sua contradição, tende a engendrar o que é novo. Nesse caso, como também nos chama atenção Plonski (2001), o conhecimento é ensejado na sua possibilidade de estabelecer relações de cooperação, rompendo com o estado de (des)conhecimento, que se impõe no quadro de relações sociais fundadas na dominação e/ou exploração de uns segmentos sobre outros, de um homem sobre outro.

Com esta perspectiva, a questão da sociedade da informação, em sua evolução para uma sociedade do conhecimento, onde os benefícios sociais deste conhecimento fossem objeto de uma redistribuição mais eqüitativa, remete-nos, ainda, a uma outra ruptura, a da fragmentação que se estrutura, agora, entre esta parcela da sociedade que agrega os lugares em rede e o 
restante da sociedade que, no dizer de Santos (2005), constitui e habita o espaço de todos.

\section{NOTAS}

1 Aqui, vale uma observação a respeito do uso dos termos "técnica" e "tecnologia" neste artigo. De modo geral, a partir desta nota, o termo "técnica" é empregado também como sinônimo de tecnologia. A sua vez, o termo "tecnologia” é usado, também a partir daqui, precisamente nas passagens em que nos referimos à evolução mais recente das técnicas, quando estas supõem cada vez mais, na sua concepção, um embasamento em pesquisa científica.

2 A respeito destes dois estudiosos pioneiros da história da informática, podemos associar, primeiro, à impulsão determinante dada por John von Newmann (1903-1957), na história das origens da informática, pelo domínio e formulação dos conhecimentos (em diversos artigos) sobre a arquitetura de computadores, sobre o modo de sua organização interna. À sua vez, constitui o legado de Norbert Wiener (1894-1964), a construção de um novo domínio do conhecimento, a Cibernética, que se define ao redor do pressuposto de que a comunicação é concebida como o comportamento da informação e de duas noções fundamentais, a da comunicação e do controle e que se condensa em dois livros fundamentais: Cybernetics or Control and Communication in the Animal and the Machine e Cybernétique et Société (BRETON, 1987, p. 134, 163).

3 Essa última afirmação se justifica no contexto dos estudos teóricos em geografia humana e, particularmente, tendo em vista o enfoque do geógrafo Milton Santos, que há muito tempo tem explicado as transformações do pós-Segunda Guerra Mundial e a constituição atual do espaço geográfico, considerando a importância crescente da incorporação de ciência, tecnologia e informação nas atividades econômicas e sociais e na própria organização do território, seja na macro-escala de um país, ou nos espaços regionais, urbanos e outros.

\section{REFERÊNCIAS}

BRETON, Philippe e PROULX, Serge. L' Explosion de la Communication: La naissance d'une nouvelle idéologie. Paris: La Découverte, 1991.

CHARDIN, Pierre Teilhard de. O Fenômeno Humano. São Paulo: Editora Cultrix, 1986.

DUCASSÉ, Pierre. Histoire des techniques. Paris: Presses Universitaires de France, 1945.

FLICHY, Patrice. Una Historia de la Comunicación Moderna: espacio público y vida privada. México: Gustavo Gili, 1993.

GIOVANNINI, Giovanni (coord.). Evolução na Comunicação: Do Sílex ao Silício. Rio de Janeiro, Nova Fronteira, 1987. 
GOMES, Cilene. Telecomunicações, Informática e Informação, e a Remodelação do Território Brasileiro. Tese (Doutorado em Geografia Humana) - Faculdade de Filosofia, Letras e Ciências Humanas, Universidade de São Paulo, São Paulo, 2001.

Informação, comunicação e a remodelação do território brasileiro. Revista Geográfica Venezolana, Vol. 43 (2), 2002, p. 265-287.

HIGOUNET, Charles. História concisa da escrita. São Paulo: Parábola, 2003.

LÉVY, Pierre. A conexão planetária: O mercado, o ciberespaço, a consciência. São Paulo: 34, 2001.

MONTIEL,Edgar.Acomunicaçãonofomento de projetos culturais parao desenvolvimento. In: UNESCO Brasil. Políticas culturais para o desenvolvimento: uma base de dados para a cultura. Brasilia, 2003.

PLONSKI, Guilherme A. Questões tecnológicas na sociedade do (des)conhecimento. Revista Ibero Americana de Ciencia, Tecnología, Sociedad y Innovación. N. 1, septiembre-diciembre de 2001.

SANTOS, Milton. A Natureza do Espaço: Técnica e Tempo. Razão e Emoção. São Paulo: Hucitec, 1996.

.Por uma outra globalização: Do pensamento único à consciência universal. Rio de Janeiro: Record, 2000. 2001 .

.O país distorcido. O Brasil, a globalização e a cidadania. São Paulo, Publifolha,

.Da totalidade ao lugar. São Paulo: Edusp, 2005.

SIQUEIRA, Holgonsi S. G. Sociedade em rede: conexões e desconexões. Jornal A Razão, dezembro de 2004.

SZABO, I. e SILVA, R.R.G. Informação e inteligência coletiva no ciberespaço: uma abordagem dialética. Ciência \& Cognição. Vol.11, 2007, p. 37-48. 